\title{
Synthesis, structure of iron(III)-containing imidazolium salts and their catalytic activity in the alkylation of aryl Grignard reagents
}

\author{
XIA Ying, YAN ChunHui, LI Zhuang, GAO HuanHuan, SUN HongMei ${ }^{*}$, SHEN Qi \& \\ ZHANG Yong
}

The Key Laboratory of Organic Synthesis of Jiangsu Province, College of Chemistry, Chemical Engineering and Materials Science, Soochow University, Suzhou 215123, China

Received May 13, 2012; accepted July 4, 2012; published online October 9, 2012

\begin{abstract}
A series of iron(III)-containing imidazolium salts of the general formula [DRim][FeX $\left.\mathrm{D}_{4}\right](\mathrm{R}=2,6$-diisopropylphenyl, $\mathrm{IPr}, \mathrm{X}=\mathrm{Cl}$, 1; $\mathrm{R}=\mathrm{IPr}, \mathrm{X}=\mathrm{Br}, \mathbf{2} ; \mathrm{R}=$ tertbutyl, ${ }^{t} \mathrm{Bu}, \mathrm{X}=\mathrm{Cl}, \mathbf{3} ; \mathrm{R}=$ isopropyl, ${ }^{i} \mathrm{Pr}, \mathrm{X}=\mathrm{Cl}, \mathbf{4} ; \mathrm{R}=$ benzyl, $\mathrm{Bn}, \mathrm{X}=\mathrm{Cl}, \mathbf{5} ; \mathrm{R}=\mathrm{Bn}, \mathrm{X}=\mathrm{Br}, \mathbf{6}$ ) have been prepared in high yields via reactions of anhydrous ferric halides with equivalent of the corresponding $N, N$-dihydrocarby-limidazolium halides, where 2-6 are novel ones. All of the complexes were characterized by elemental analysis, Raman spectroscopy, electrospray ionization mass spectroscopy, and X-ray crystallography for $\mathbf{1}$ and $\mathbf{2}$. All of them were non-hygroscopic and air-stable, with four of them existing as solids (1-4) and two as liquids (5 and $\mathbf{6})$ at room temperature. A preliminary catalytic study on the coupling of 4-tolylmagnesium bromide with cyclohexyl bromide revealed that $\mathbf{1}$ and $\mathbf{3}$ possessed the highest activity. In comparison, $\mathbf{2}, \mathbf{4}$ and $\mathbf{5}$ exhibited moderate activity and the least active complex was $\mathbf{6}$.
\end{abstract}

iron(III) complex, imidazolium salt, cross-coupling, aryl Grignard reagent, alkyl halide

Citation: $\quad \mathrm{Xia} \mathrm{Y,} \mathrm{Yan} \mathrm{C} \mathrm{H,} \mathrm{Li} \mathrm{Z,} \mathrm{et} \mathrm{al.} \mathrm{Synthesis,} \mathrm{structure} \mathrm{of} \mathrm{iron(III)-containing} \mathrm{imidazolium} \mathrm{salts} \mathrm{and} \mathrm{their} \mathrm{catalytic} \mathrm{activity} \mathrm{in} \mathrm{the} \mathrm{alkylation} \mathrm{of} \mathrm{aryl} \mathrm{Grignard}$ reagents. Chin Sci Bull, 2013, 58: 493-499, doi: 10.1007/s11434-012-5513-4

During recent decade the development of iron-based catalysts has received increasing attention with renewed enthusiasm for a variety of cross-coupling reactions since iron is more cost-effective and environmental benign than palladium or nickel [1].

Well-defined iron complexes, developed for the crosscoupling reaction of aryl Grignard reagents with primary or secondary alky halides bearing $\beta$-hydrogens, represent one of the most successful examples of iron-based catalytic systems in this area, which is mostly owing to their ability to efficiently suppress $\beta$-H elimination and their potentiality from a mechanistic perspective [2]. Related iron-based complexes, which including organoiron(-II) complexes [2,3], iron(III) salen-type complexes [4], iron(III) imine complexes [5] and iron(III) complexes of different amine-bridged bis(phenolate) liagnds [6-9], have been

*Corresponding author (email: sunhm@ suda.edu.cn) shown to be capability in this regard. $\mathrm{Fe}(\mathrm{acac})_{3}(\mathrm{acac}=$ acetylacetonate) are also active [10], although the addition of an amine additive was required to achieve a higher yield of the cross-coupled product [11]. Notably, an easily prepared iron(III)-containing imidazolium salt [bmim] $\left[\mathrm{FeCl}_{4}\right]$ (bmim = 1-butyl-3-methylimidazolium cation) can be used as a recyclable catalyst for the aryl Grignard cross-coupling of alkyl halides [12]. The use of imidazolium chloride can modify the highly hygroscopic $\mathrm{FeCl}_{3}$ into an non-hygroscopic and air-stable complex, which provides a practical strategy for the design of iron(III)-based catalyst with potential large-scale applications [11]. [bmim] $\left[\mathrm{FeCl}_{4}\right]$ has already been successfully used as a catalyst in other organic transformations, including the Friedel-Crafts sulfonylation of aromatics [13], a Biginelli condensation for the synthesis of dihydropyrimidinones [14], 2,5-norbornadiene dimerization [15], oxidative desulfurization of fuels [16], the glycolysis of poly(ethylene terephthalate) [17], and the regioselective benzylation of arenes and heteroarenes [18]. 
However, the liquid state of this ionic iron(III) complex may lead to some problems with structural definition and handling. In this context, the careful design and optimization of catalyst structure to provide an alternative easy-touse iron(III)-based analogue is of great interest.

In recent years there is an increasing interest in the application of ionic liquids (ILs) to modify transition metalbased homogeneous catalysts in terms of stability, activity, low toxicity and reusability of the catalysts [19]. Of various types of ILs available, imidazolium salts are the most popular one employed. In general, they are capable of being tuned with relative ease by the selection of the appropriate cation and anion combination. However, as far as we know, there are few works about the structural character and reactivity of the iron(III)-based catalysts modified by imidazolium cations [20], even if the study of metal complexation in ionic liquids (ILs) is of highly desirable to support the extensive applications of MetILs (so called transition metal containing ILs) that are currently under development [21]. In fact, structural data for ionic iron(III)-containing complexes of the type [imidazolium cation] $\left[\mathrm{FeX}_{4}\right]$ have been only scarcely reported, and the first structural data for an oily iron(III) complex, $\left[\mathrm{C}_{2} \mathrm{mim}\right]\left[\mathrm{FeCl}_{4}\right]\left(\mathrm{C}_{2} \mathrm{mim}=1\right.$-ethyl3-methylimidazolium cation), was recently determined by Mudring and co-workers [22] via the method of the in situ crystal growth. Another structural data for a 1,3-dibutylbenzimidazolium-based ionic iron(III) complex, $\left[\left(\mathrm{C}_{4} \mathrm{H}_{9}\right)_{2}-\right.$ bim $]\left[\mathrm{FeCl}_{4}\right] \quad\left[\left(\mathrm{C}_{4} \mathrm{H}_{9}\right)_{2}\right.$ bim = 1,3-dibutylbenzimidazolium cation], were published soon after [23].

Very recently, we developed a 1,3-bis(2,6-diisopropylphenyl)imidazolium-modified iron(III)-containing complex [DIPrim] $\left[\mathrm{FeCl}_{4}\right]$ ( $\mathrm{IPr}=2,6$-diisopropylphenyl), which was obtained as yellow-green crystals and could be used as an efficient and recyclable catalyst for cross-coupling of aryl Grignard reagents with alkyl halides [24]. As a continuation of our work on the development of iron-based catalysts for carbon-carbon bond formation [24,25], herein we reported the synthesis and structural characterization of a series of iron(III)-containing imidazolium salts (1-6) and their use in the catalytic cross-coupling of aryl Grignard reagents with alky halides bearing $\beta$-hydrogens.

\section{Experimental}

Since anhydrous $\mathrm{FeCl}_{3}, \mathrm{FeBr}_{3}$, 1,3-bis(2,6-diisopropylphenyl)imidazolium chloride ([DIPrim]Cl), 1,3-bis(2,6diisopropylphenyl)imidazolium bromide ([DIPrim] Br), 1,3ditertbutylimidazolium chloride ([D $\left.\left.{ }^{t} \mathrm{Buim}\right] \mathrm{Cl}\right), 1,3$-diisopropylimidazolium chloride $\left(\left[\mathrm{D}^{i}\right.\right.$ Prim $\left.] \mathrm{Cl}\right), 1,3$-dibenzylimidazolium chloride (DBnim]Cl) and 1,3-dibenzylimidazolium bromide ([DBnim]Br) are hydrophilic, all manipulations were carried out under an atmosphere of dry argon with rigorous exclusion of air and moisture using standard Schlenk techniques.

\subsection{Materials}

All organic solvents were freshly distilled from Na/benzophenone ketyl under pure argon prior to use. Anhydrous $\mathrm{FeCl}_{3}, \mathrm{FeBr}_{3}$ and organic reagents used for cross-coupling reactions were bought from Acros Organics, Aldrich, and Alfa Aesar. 4-Methylphenylmagnesium bromide was diluted prior to use. ([DIPrim]Cl) [26], ([DIPrim]Br) [26], ([D ${ }^{t}$ Buim $\left.] \mathrm{Cl}\right)$ [27], ([D Prim]Cl) [28], (DBnim]Cl) [28], ([DBnim]Br) [28] and [DIPrim] $\left[\mathrm{FeCl}_{4}\right]$ (1) [24] was prepared by established methods.

\subsection{Synthesis}

(i) Synthesis of [DIPrim] $\left[\mathrm{FeBr}_{4}\right]$ (2). A Schlenk flask was charged with [DIPrim]Br $(1.50 \mathrm{~g}, 3.20 \mathrm{mmol})$, THF $(20 \mathrm{~mL})$ and a stirring bar. To this suspension, $\mathrm{FeBr}_{3}(0.95 \mathrm{~g}, 3.20$ $\mathrm{mmol}$ ) in $20 \mathrm{~mL}$ of THF was added. The reaction mixture was stirred for $2 \mathrm{~h}$ at room temperature, filtered, and evaporated to dryness. The residue was recrystallized from THF and hexane to yield orange-red crystals (2.28 g, 93\%), mp: $139.50^{\circ} \mathrm{C}$. Anal. calcd. for $\mathrm{C}_{27} \mathrm{H}_{37} \mathrm{~N}_{2} \mathrm{FeBr}_{4}$ : C, 42.39; H, 4.87; N, 3.66. Found: C, 42.26; H, 4.54; N, 3.68. MS (ESI+): $\mathrm{m} / \mathrm{z} 389.2944\left[\mathrm{C}_{27} \mathrm{H}_{37} \mathrm{~N}_{2}\right]^{+}$(100\%). Raman: $203.463 \mathrm{~cm}^{-1}$ $\left(\left[\mathrm{FeBr}_{4}\right]^{-}\right)$.

(ii) Synthesis of $\left[\mathrm{D}^{t} \mathrm{Buim}\right]\left[\mathrm{FeCl}_{4}\right](3)$. By the procedure analogous to that described for 2 , the product [ $\mathrm{D}^{t} \mathrm{Buim}$ ] $\left[\mathrm{FeCl}_{4}\right]$ was precipitated as yellow solids in $95 \%$ yield (1.63 g). mp: $82.07^{\circ} \mathrm{C}$. Anal. calcd. for $\mathrm{C}_{11} \mathrm{H}_{21} \mathrm{~N}_{2} \mathrm{FeCl}_{4}$ : C, 34.86; H, 5.59; N, 7.39. Found: C, 34.72; H, 5.98; N, 7.30. MS (ESI+): $\mathrm{m} / z$ 181.1704 $\left[\mathrm{C}_{11} \mathrm{H}_{21} \mathrm{~N}_{2}\right]^{+}(100 \%)$. Raman: 335.956 $\mathrm{cm}^{-1}\left(\left[\mathrm{FeCl}_{4}\right]^{-}\right)$.

(iii) Synthesis of $\left[\mathrm{D}^{i} \mathrm{Prim}\right]\left[\mathrm{FeCl}_{4}\right](\mathbf{4}) . \quad$ By the procedure analogous to that described for $\mathbf{2}$, the product [D ${ }^{i}$ Prim] $\left[\mathrm{FeCl}_{4}\right]$ was precipitated as yellow-brown solids in $91 \%$ yield $(0.85 \mathrm{~g})$, mp: $74.10^{\circ} \mathrm{C}$. Anal. calcd. for $\mathrm{C}_{9} \mathrm{H}_{17} \mathrm{Cl}_{4} \mathrm{~N}_{2} \mathrm{Fe}$ : C, 30.81; H, 4.88; N, 7.98. Found: C, 30.42; H, 4.78; N, 7.74. MS (ESI+): $m / z 153.1389\left[\mathrm{C}_{9} \mathrm{H}_{17} \mathrm{~N}_{2}\right]^{+}(100 \%)$. Raman: $335.956 \mathrm{~cm}^{-1}\left(\left[\mathrm{FeCl}_{4}\right]^{-}\right)$.

(iv) Synthesis of [DBnim] $\left[\mathrm{FeCl}_{4}\right](\mathbf{5}) . \quad$ By the procedure analogous to that described for $\mathbf{2}$, the product [DBnim] $\left[\mathrm{FeCl}_{4}\right]$ was precipitated as yellow-brown oil in $83 \%$ yield $(1.07 \mathrm{~g})$. Anal. Calcd. for $\mathrm{C}_{17} \mathrm{H}_{17} \mathrm{Cl}_{4} \mathrm{~N}_{2} \mathrm{Fe}: \mathrm{C}, 45.68 ; \mathrm{H}, 3.83$; $\mathrm{N}, 6.27$. Found: C, 44.28; H, 4.00; N, 6.20. MS (ESI+): $\mathrm{m} / \mathrm{z}$ $249.1386\left[\mathrm{C}_{17} \mathrm{H}_{17} \mathrm{~N}_{2}\right]^{+}$(100\%). Raman: $333.096 \mathrm{~cm}^{-1}$ $\left(\left[\mathrm{FeCl}_{4}\right]^{-}\right)$.

(v) Synthesis of [DBnim] $\left[\mathrm{FeBr}_{4}\right](\mathbf{6}) . \quad$ By the procedure analogous to that described for 2 , the product [DBnim] [ $\left.\mathrm{FeBr}_{4}\right]$ was precipitated as black-red oil in $88 \%$ yield (1.91 g). Anal. calcd. for $\mathrm{C}_{17} \mathrm{H}_{17} \mathrm{Br}_{4} \mathrm{~N}_{2} \mathrm{Fe}: \mathrm{C}, 32.68 ; \mathrm{H}, 2.74 ; \mathrm{N}$, 4.48. Found: C, 32.49; H, 2.62; N, 4.31. MS (ESI+): $\mathrm{m} / \mathrm{z}$ $249.1390\left[\mathrm{C}_{17} \mathrm{H}_{17} \mathrm{~N}_{2}\right]^{+}$(100\%). Raman: $203.463 \mathrm{~cm}^{-1}$ $\left(\left[\mathrm{FeBr}_{4}\right]^{-}\right)$.

(vi) Typical cross-coupling procedure. A Schlenk tube was charged with iron(III)-based catalyst $(0.01 \mathrm{mmol})$, alkyl 
bromide $(1.00 \mathrm{mmol}), n$-hexadecane $(0.10 \mathrm{mmol})$ as internal standard, diethyl ether $(0.8 \mathrm{~mL})$, and a stirring bar. 4Methylphenylmagnesium bromide $(1.50 \mathrm{mmol}, 1.07 \mathrm{~mol} / \mathrm{L}$ solution in diethyl ether) was added to this solution at $30^{\circ} \mathrm{C}$. The resulting solution changed color to black and was then stirred for $20 \mathrm{~min}$ at $30^{\circ} \mathrm{C}$. After the reaction was quenched by adding dilute hydrochloric acid $(1.0 \mathrm{~mol} / \mathrm{L}, 0.5 \mathrm{~mL})$, the mixture was extracted with diethyl ether $(3 \times 4 \mathrm{~mL})$. The yield of the desired product is determined by GC analysis, using $n$-hexadecane as an internal standard.

\subsection{Analyses}

Carbon, hydrogen, and nitrogen analyses were preformed by direct combustion with a Carlo-Erba EA-1110 instrument. The Raman spectra were recorded on a LabRAM HR800 spectrometer. Electrospray Ionization-Mass spectrum (ESI-MS) data were recorded on a 6220 AccurateMass TOF LC/MS instrument. Gas chromatographic (GC) analysis was performed on a Varian CP-3800 instrument equipped with a flame ionization detector and a OV-101 capillary column $(30 \mathrm{~m} \times 0.32 \mathrm{~mm}$ i.d., $0.10 \mu \mathrm{m}$ film $)$. The oven temperature was held at $80^{\circ} \mathrm{C}$ for $2 \mathrm{~min}$, increased to $280^{\circ} \mathrm{C}$ at $10^{\circ} \mathrm{C} / \mathrm{min}$, and held for $2 \mathrm{~min}$. The melt points were determined on a Diamond DSC (Perkin Elmer) using powder samples under $\mathrm{N}_{2}$ atmosphere $(50 \mathrm{~mL} / \mathrm{min})$. The system was heated from 50 to $250^{\circ} \mathrm{C}$ at $20^{\circ} \mathrm{C} / \mathrm{min}$.

\subsection{X-ray structural determination}

Suitable crystals of complexes $\mathbf{1}$ and $\mathbf{2}$ were each sealed in a thin-walled glass capillary for single-crystal X-ray structural analysis. Diffraction data were collected on a Rigaku Mercury CCD area detector at 223(2) K. The structure was solved by direct methods and refined by full-matrix leastsquares procedures based on $F^{2}$. All non-hydrogen atoms were refined with anisotropic displacement coefficients. Hydrogen atoms were treated as idealized contributions. The structures were solved and refined using SHELXL-97 and SHELXL-97 programs, respectively. Crystal data and collection and main refinement parameters are given in Table 1.

\section{Results and discussion}

\subsection{Synthesis and characterization of 2-6}

The target imidazolium salt of iron(III) [DIPrim] $\left[\mathrm{FeCl}_{4}\right]$ (1) was easily synthesized according to a published procedure [24]. As shown in Scheme 1, similar reactions with other imidazolium halides provide the corresponding iron(III)containing imidazolium salts $\mathbf{2 - 6}$ in nearly quantitative yields.

Although anhydrous $\mathrm{FeCl}_{3}, \mathrm{FeBr}_{3}$ and the imidazolium halides are hydrophilic, the target iron(III)-containing
Table 1 X-ray crystallographic data for $\mathbf{1}$ and $\mathbf{2}$

\begin{tabular}{|c|c|c|}
\hline & $\mathbf{1} \cdot \mathrm{C}_{4} \mathrm{H}_{8} \mathrm{O}$ & $2 \cdot \mathrm{C}_{4} \mathrm{H}_{8} \mathrm{O}$ \\
\hline Empirical formula & $\mathrm{C}_{31} \mathrm{H}_{45} \mathrm{Cl}_{4} \mathrm{FeN}_{2} \mathrm{O}$ & $\mathrm{C}_{31} \mathrm{H}_{45} \mathrm{Br}_{4} \mathrm{FeN}_{2} \mathrm{O}$ \\
\hline Formular weight & 659.34 & 837.18 \\
\hline Temperature (K) & $223(2)$ & $223(2)$ \\
\hline$\lambda(\mathrm{Mo} \mathrm{K} \alpha)(\AA)$ & 0.71075 & 0.71075 \\
\hline Crystal system & Triclinic & Triclinic \\
\hline Space group & $\mathrm{P}-1$ & $\mathrm{P}-1$ \\
\hline$a(\AA)$ & $10.010(2)$ & $10.084(1)$ \\
\hline$b(\AA)$ & $12.716(3)$ & $12.782(2)$ \\
\hline$c(\AA)$ & $14.348(3)$ & $14.770(2)$ \\
\hline$\alpha\left(^{\circ}\right)$ & $82.947(7)$ & $81.951(9)$ \\
\hline$\beta\left(^{\circ}\right)$ & $82.249(8)$ & $81.120(9)$ \\
\hline$\gamma\left({ }^{\circ}\right)$ & $78.986(8)$ & $77.836(8)$ \\
\hline$V\left(\AA^{3}\right)$ & $1767.5(7)$ & $1827.3(4)$ \\
\hline$Z$ & 2 & 2 \\
\hline$D_{\text {calc }}\left(\mathrm{g} \mathrm{cm}^{-3}\right)$ & 1.239 & 1.522 \\
\hline Absorption coefficent $\left(\mathrm{mm}^{-1}\right)$ & 0.753 & 4.810 \\
\hline$F(000)$ & 694 & 838 \\
\hline Crystal size & $\begin{array}{c}0.40 \mathrm{~mm} \times 0.20 \\
\mathrm{~mm} \times 0.20 \mathrm{~mm}\end{array}$ & $\begin{array}{c}0.50 \mathrm{~mm} \times 0.40 \\
\mathrm{~mm} \times 0.10 \mathrm{~mm}\end{array}$ \\
\hline$\theta$ range $\left(^{\circ}\right)$ & $3.17-25.50$ & $3.09-27.50$ \\
\hline No. of reflns collected & 12741 & 17717 \\
\hline No. of reflns unique, $R_{\text {int }}$ & $6449,0.0518$ & $8223,0.0589$ \\
\hline Goodness-of-fit on $F^{2}$ & 1.069 & 0.936 \\
\hline$R_{1}, w R_{2}[I>2 \sigma(I)]$ & $0.0698,0.1495$ & $0.0567,0.1265$ \\
\hline$R_{1}, w R_{2}$ (all data) & $0.1101,0.1718$ & $0.1335,0.1562$ \\
\hline
\end{tabular}

$$
\begin{aligned}
& \mathrm{R}-\widehat{\mathrm{C}}^{\mathrm{N}-\mathrm{R}}+\mathrm{FeX}_{3} \frac{\mathrm{THF}}{\text { r.t., } 3 \mathrm{~h}} \mathrm{R}-\stackrel{\mathrm{NeX}_{4}^{\Theta}}{\mathrm{N}-\mathrm{R}} \\
& \mathrm{R}=\text { 2,6-diisopropylphenyl, } \mathrm{X}=\mathrm{Br} \text {, [DIPrim] }\left[\mathrm{FeBr}_{4}\right], \mathbf{2} \text {, yield: } 93 \% \\
& \left.\mathrm{R}=\text { tert-butyl, } \mathrm{X}=\mathrm{Cl} \text {, [D }{ }^{t} \mathrm{Buim}\right]\left[\mathrm{FeCl}_{4}\right], \mathbf{3} \text {, yield: } 95 \% \\
& \mathrm{R}=\text { iso-propyl, } \mathrm{X}=\mathrm{Cl},\left[\mathrm{D}^{i} \text { Prim] }\left[\mathrm{FeCl}_{4}\right], \mathbf{4} \text {, yield: } 91 \%\right. \\
& \mathrm{R}=\text { benzyl, } \mathrm{X}=\mathrm{Cl} \text {, [DBnim][FeCl}] \text { ], 5, yield: } 83 \% \\
& \mathrm{R}=\text { benzyl, } \mathrm{X}=\mathrm{Br} \text {, [DBnim] }\left[\mathrm{FeBr}_{4}\right], 6 \text {, yield: } 88 \% \text {. }
\end{aligned}
$$

Scheme 1 Synthesis of iron(III)-containing imidazolium salts 2-6.

imidazolium salts 1-6 are non-hygroscopic and air-stable, and four of them (1-4) existed as solids at room temperature, making them easier to handle. Better solubility profiles were observed for 1-6 than in the corresponding imidazolium salts, and all of them dissolved easily in THF. The difference in solubility between the imidazolium halide and the corresponding iron(III)-containing imidazolium salt facilitated the effective purification of the target product.

The formation of ionic iron(III) complexes 1-6 was supported by elemental analysis, Raman spectroscopy, electrospray ionization mass spectroscopy (ESI-MS) and X-ray crystallography for complexes $\mathbf{1}$ and $\mathbf{2}$. The Raman spectra of 1-6 confirmed the existence of $\left[\mathrm{FeX}_{4}\right]^{-}$anions in them. As seen from Figures 1 and 2, a predominant feature of the spectra of 3-5 was one strong peak at the range of 333-336 $\mathrm{cm}^{-1}$, whereas the spectra of $\mathbf{2}$ and $\mathbf{6}$ showed only one 

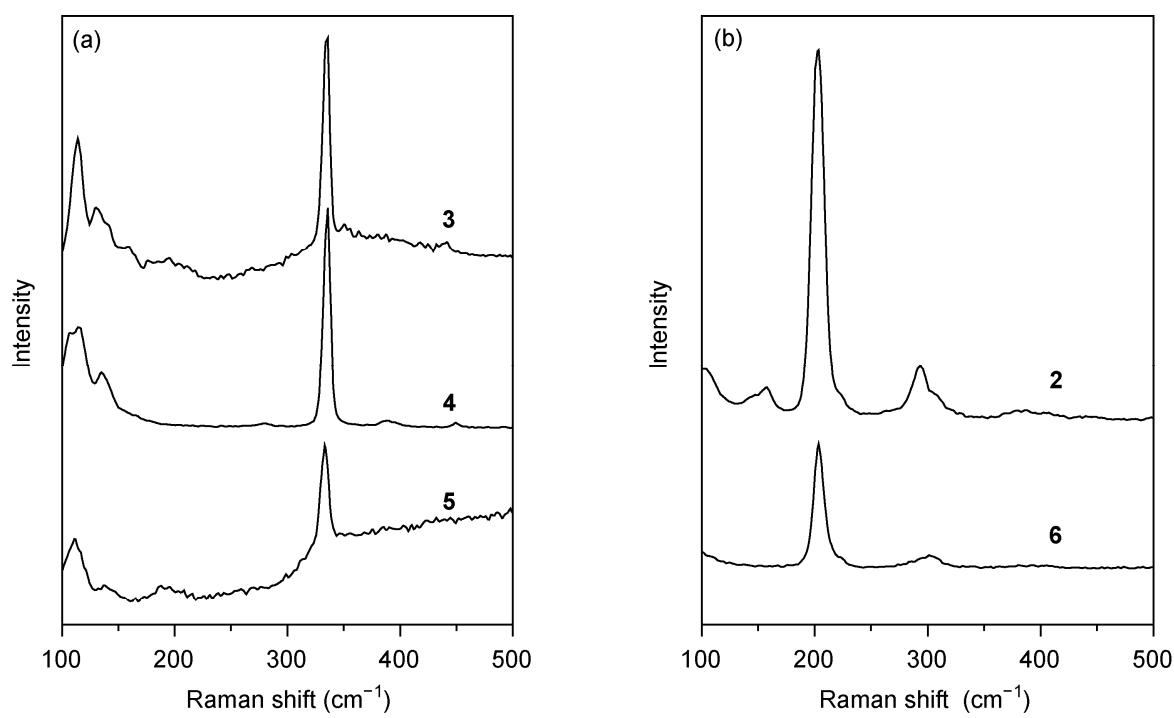

Figure 1 Raman spectra of 3-5 (a) and 2 and 6 (b).

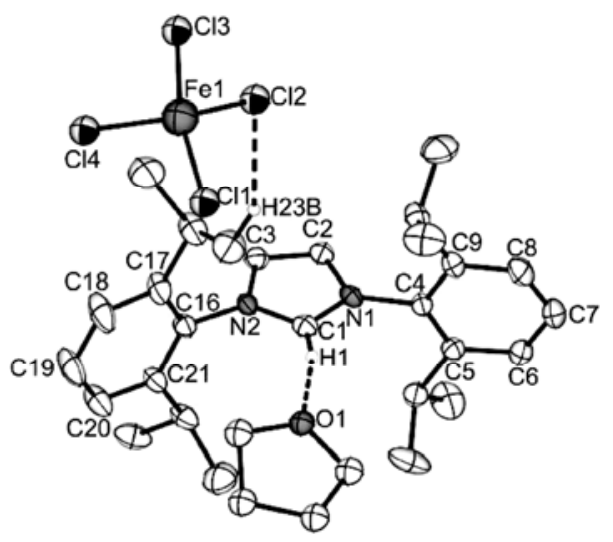

Figure 2 Molecular structure of $1 \cdot \mathrm{C}_{4} \mathrm{H}_{8} \mathrm{O}$ showing hydrogen bonds with thermal ellipsoids at the $30 \%$ probability level. Hydrogen atoms (except the hydrogen bonded hydrogen atoms) have been omitted for clarity.

strong peak at $c a .203 \mathrm{~cm}^{-1}$. These data coincided very closely to the literature values for the $\left[\mathrm{FeCl}_{4}\right]^{-}[29]$ and $\left[\mathrm{FeBr}_{4}\right]^{-}$[30] species, respectively. The positive ion ESIMS spectra of 2-6 were used to establish the presence of the imidazolium cations, and in all cases a peak with an intensity of almost $100 \%$ indicative of the parent cations was observed. Thus, these characteristic results confirmed that complexes 2-6 consisted of [DRim] $\left[\mathrm{FeX}_{4}\right](\mathrm{X}=\mathrm{Cl}$ and $\mathrm{Br})$. The ${ }^{1} \mathrm{H}$ NMR spectra of them, however, were less informative because they exhibit broad, shifted peaks with paramagnetism.

\subsection{Crystal structures of 1 and 2}

Single crystals of $\mathbf{1}$ and $\mathbf{2}$ suitable for an X-ray crystal structure determination were obtained from THF at $-10^{\circ} \mathrm{C}$. The selected bond lengths and angles are listed in Table 2. Their molecular structures are depicted in Figures 2 and 3,
Table 2 Selected bond lengths $(\AA)$ and angles $\left({ }^{\circ}\right)$ for $\mathbf{1}$ and 2

\begin{tabular}{|c|c|c|c|}
\hline \multicolumn{2}{|c|}{$\mathbf{1} \cdot \mathrm{C}_{4} \mathrm{H}_{8} \mathrm{O}$} & \multicolumn{2}{|c|}{$2 \cdot \mathrm{C}_{4} \mathrm{H}_{8} \mathrm{O}$} \\
\hline $\mathrm{Fe}(1)-\mathrm{Cl}(1)$ & $2.186(2)$ & $\mathrm{Fe}(1)-\mathrm{Br}(1)$ & $2.331(1)$ \\
\hline $\mathrm{Fe}(1)-\mathrm{Cl}(2)$ & $2.193(2)$ & $\mathrm{Fe}(1)-\mathrm{Br}(2)$ & $2.329(1)$ \\
\hline $\mathrm{Fe}(1)-\mathrm{Cl}(3)$ & $2.185(2)$ & $\mathrm{Fe}(1)-\mathrm{Br}(3)$ & $2.335(1)$ \\
\hline $\mathrm{Fe}(1)-\mathrm{Cl}(4)$ & $2.184(2)$ & $\mathrm{Fe}(1)-\mathrm{Br}(4)$ & $2.326(1)$ \\
\hline $\mathrm{Cl}(4)-\mathrm{Fe}(1)-\mathrm{Cl}(3)$ & $109.11(6)$ & $\operatorname{Br}(4)-\mathrm{Fe}(1)-\mathrm{Br}(3)$ & 111.01(4) \\
\hline $\mathrm{Cl}(4)-\mathrm{Fe}(1)-\mathrm{Cl}(1)$ & $110.16(7)$ & $\operatorname{Br}(4)-\mathrm{Fe}(1)-\mathrm{Br}(1)$ & $110.48(5)$ \\
\hline $\mathrm{Cl}(3)-\mathrm{Fe}(1)-\mathrm{Cl}(1)$ & $108.58(6)$ & $\operatorname{Br}(3)-\mathrm{Fe}(1)-\operatorname{Br}(1)$ & $109.44(4)$ \\
\hline $\mathrm{Cl}(4)-\mathrm{Fe}(1)-\mathrm{Cl}(2)$ & 109.98(7) & $\operatorname{Br}(4)-\mathrm{Fe}(1)-\mathrm{Br}(2)$ & $108.09(4)$ \\
\hline $\mathrm{Cl}(3)-\mathrm{Fe}(1)-\mathrm{Cl}(2)$ & $108.06(6)$ & $\operatorname{Br}(3)-\mathrm{Fe}(1)-\mathrm{Br}(2)$ & $108.30(4)$ \\
\hline $\mathrm{Cl}(1)-\mathrm{Fe}(1)-\mathrm{Cl}(2)$ & $110.90(6)$ & $\operatorname{Br}(1)-\mathrm{Fe}(1)-\mathrm{Br}(2)$ & $109.48(4)$ \\
\hline \multicolumn{4}{|c|}{ Dihedral angle between benzene ring and the imidazolium ring } \\
\hline \multicolumn{4}{|l|}{ Plane } \\
\hline $\mathrm{N} 1 \mathrm{C} 1 \mathrm{~N} 2 / \mathrm{IPr}(1)$ & $86.6(1)$ & $\mathrm{C} 1 \mathrm{~N} 1 \mathrm{C} 2 / \operatorname{IPr}(1)$ & $87.7(2)$ \\
\hline $\mathrm{N} 1 \mathrm{C} 1 \mathrm{~N} 2 / \mathrm{IPr}(2)$ & $87.7(2)$ & $\mathrm{C} 1 \mathrm{~N} 2 \mathrm{C} 3 / \operatorname{IPr}(2)$ & $87.4(2)$ \\
\hline $\operatorname{IPr}(1) / \operatorname{IPr}(2)$ & $37.4(1)$ & $\operatorname{IPr}(1) / \operatorname{IPr}(2)$ & $37.9(2)$ \\
\hline \multicolumn{4}{|l|}{ Hydrogen bonds } \\
\hline $\mathrm{C}(1)-\mathrm{H}(1) \cdots \mathrm{O}(1)$ & 2.13 & $\mathrm{C}(1)-\mathrm{H}(1) \cdots \mathrm{O}(1)$ & 2.16 \\
\hline $\mathrm{C}(3)-\mathrm{H}(3) \cdots \mathrm{Cl}(2)$ & 2.90 & & \\
\hline $\mathrm{C}(1)-\mathrm{H}(1)-\mathrm{O}(1)$ & $164.9(3)$ & $\mathrm{C}(1)-\mathrm{H}(1)-\mathrm{O}(1)$ & $158.7(4)$ \\
\hline $\mathrm{C}(3)-\mathrm{H}(3)-\mathrm{Cl}(2)$ & $145.0(4)$ & & \\
\hline
\end{tabular}

respectively.

As shown in Figures 2 and 3, each of the two molecular structures contains one imidazolium [DIPrim $]^{+}$cation, one $\left[\mathrm{FeX}_{4}\right]^{-}$anion, and one additional THF molecule. In $\mathbf{1}$ and 2, the bond distances and angles within the imidazolium ring and side chain were almost same in values, accompanied by the similar orientation of the IPr chain. Each plane of the phenyl ring in $\mathbf{1}$ and $\mathbf{2}$ was oriented nearly perpendicular to the plane of imidazolium ring with the dihedral angles equal to $86.6(1)^{\circ}$ and $87.7(2)^{\circ}$ for $\mathbf{1}$, and $87.7(2)^{\circ}$ and 


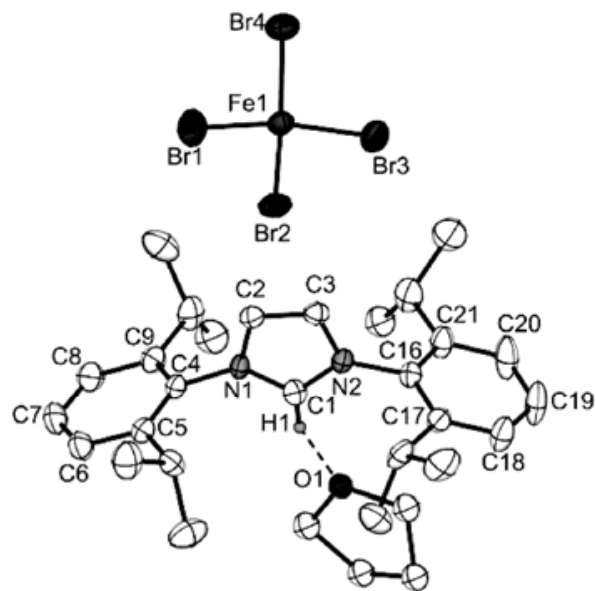

Figure 3 Molecular structure of $2 \cdot \mathrm{C}_{4} \mathrm{H}_{8} \mathrm{O}$ showing hydrogen bonds with thermal ellipsoids at the $30 \%$ probability level. Hydrogen atoms (except the hydrogen bonded hydrogen atoms) have been omitted for clarity.

$87.4(2)^{\circ}$ for 2 , meanwhile they arranged themselves with a dihedral angle of 37.4(1) ${ }^{\circ}$ in $\mathbf{1}$ and of $37.9(2)^{\circ}$ in $\mathbf{2}$.

The $\left[\mathrm{FeCl}_{4}\right]^{-}$anion in $\mathbf{1}$ formed a slightly distorted tetrahedron geometry around the iron center with the four $\mathrm{Fe}-\mathrm{Cl}$ bond distances lying in a range of 2.184(2)-2.193(2) $\AA$, which were in agreement with values found in other iron(III)-containing imidazolium salts [22,23]. The $\mathrm{Cl}-\mathrm{Fe}-$ $\mathrm{Cl}$ angles of $\left[\mathrm{FeCl}_{4}\right]^{-}$were between $108.06(6)^{\circ}$ and $110.90(6)^{\circ}$ with a mean value of $109.47^{\circ}$, which was close to the ideal tetrahedral angle at $-50^{\circ} \mathrm{C}$ [22]. Similarly, the $\left[\mathrm{FeBr}_{4}\right]^{-}$anion in $\mathbf{2}$ also had a slightly distorted tetrahedral geometry, because the six $\mathrm{Br}-\mathrm{Fe}-\mathrm{Br}$ angles ranging from $108.09(4)^{\circ}$ to $111.01(4)^{\circ}$ were slightly different from each other, although each of the four $\mathrm{Fe}-\mathrm{Br}$ bond lengths was almost the same (2.326(1)-2.335(1) $\AA$ ). These values were in the expected range as found for other complexes containing $\left[\mathrm{FeBr}_{4}\right]^{-}$anions [31].

Hydrogen bonding is very important for MetILs, especially the hydrogen bonding interaction between the imidazolium cation and halide anion is well established [21-23]. However, in $\mathbf{1}$ only one typical hydrogen bond of $2.90 \AA$ are formed between the chlorine atom of $\left[\mathrm{FeCl}_{4}\right]^{-}$anion and the hydrogen atom of the isopropyl group in the imidazolium cation, whereas none of the cation-anion interatomic distances found in $\mathbf{2}$ fell within the generally accepted range for typical hydrogen bonding interactions [32]. Of note, the more acidic hydrogen atom at the 2-position of the imidazolium ring was not involved in the hydrogen bonding network between the imidazolium cation and $\left[\mathrm{FeX}_{4}\right]^{-}$anion. Thus, both $\mathbf{1}$ and $\mathbf{2}$ can be described as a simple collection of ion pairs, which is somewhat different from those found either in $\left[\mathrm{C}_{2} \mathrm{mim}\right]\left[\mathrm{FeCl}_{4}\right]$ [22] or in $\left[\left(\mathrm{C}_{4} \mathrm{H}_{9}\right)_{2}\right.$ bim $]\left[\mathrm{FeCl}_{4}\right]$ [23]. The unique patterns in them, especially in $\mathbf{2}$, are mostly attributed to the steric bulkiness of the aryl-substituted imidazolium cation [25].

\subsection{Catalysis of 1-6}

The reactivity of 1-6 was tested in the Kumada-Corriu reaction to disclose any effect due to the structural variation of an iron(III)-containing imdazolium salt on catalysis. The reaction outlined in Equation 1 was chosen as a model system, as it represents a prototype cross-coupling of aryl Grignard reagents with alkyl halides bearing $\beta$-hydrogens $[4,6,7,24]$. The results obtained are summarized in Table 3.

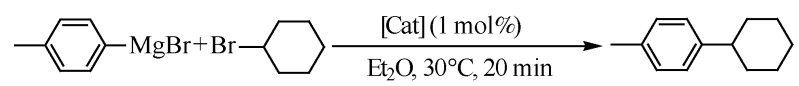

It is clear that all of iron(III)-containing imidazolium salts 1-6 provided good to excellent yields of the desired coupling product using cyclohexyl bromide as a starting reagent, whereas $\mathrm{FeCl}_{3}$ alone afforded the product in a significantly low yield (Table 3, entry 2). The mixture of $\mathrm{FeCl}_{3}$ and [DIPrim] $\mathrm{Cl}$ in a 1:1 molar ratio exhibited moderate activity and provided the coupling product in $62 \%$ yield (Table 3, entry 3). As can be seen from Table 3, 1 and $\mathbf{3}$ exhibit the highest catalytic activity for the cross-coupling of 4tolylmagnesiumbromide with cyclohexyl bromide, providing almost quantitative yields of the desired coupling products (Table 3, entries 4 and 7). Under the same conditions, a considerably lower activity was seen when $\mathbf{4}$ or $\mathbf{5}$ was

Table 3 Activities of catalytic systems based on iron(III) complexes ${ }^{\text {a) }}$

\begin{tabular}{|c|c|c|c|c|c|}
\hline Entry & Catalyst & Yield $^{\text {b) }}$ & Entry & Catalyst & Yield $^{\text {b) }}$ \\
\hline 1 & {$[\mathrm{DIPrim}] \mathrm{Cl}$} & 3 & 7 & {$\left[\mathrm{D}^{\mathrm{t}} \mathrm{Buim}\right]\left[\mathrm{FeCl}_{4}\right](\mathbf{3})$} & 98 \\
\hline 2 & $\mathrm{FeCl}_{3}$ & 14 & 8 & {$\left[\mathrm{D}^{\mathrm{i}}\right.$ Prim $]\left[\mathrm{FeCl}_{4}\right](\mathbf{4})$} & 76 \\
\hline 4 & {$[$ DIPrim $]\left[\mathrm{FeCl}_{4}\right](\mathbf{1})$} & 97 & 10 & {$[\mathrm{DBnim}]\left[\mathrm{FeBr}_{4}\right](\mathbf{6})$} & 67 \\
\hline 5 & {$[\mathrm{DIPrim}]\left[\mathrm{FeBr}_{4}\right](\mathbf{2})$} & 88 & $11^{\mathrm{d})}$ & {$[\mathrm{bmim}]\left[\mathrm{FeCl}_{4}\right]$} & 89 \\
\hline $6^{\mathrm{c})}$ & {$[$ DIPrim $]\left[\mathrm{FeBr}_{3}\right] \cdot \mathrm{C}_{4} \mathrm{H}_{8} \mathrm{O}$} & 74 & $12^{\mathrm{e})}$ & {$\left[\mathrm{Fe}(\mathrm{IPr}) \mathrm{Br}_{3}\right](\mathrm{HIPr})_{3} \cdot \mathrm{C}_{7} \mathrm{H}_{8}$} & 96 \\
\hline
\end{tabular}

a) Iron(III)-containing catalyst $(1.0 \mathrm{~mol} \%)$, cyclohexyl bromide $(1.0 \mathrm{mmol}), 4-\mathrm{MeC}_{6} \mathrm{H}_{4} \mathrm{MgBr}(1.5 \mathrm{mmol}), 4-\mathrm{MeC} \mathrm{H}_{4} \mathrm{MgBr}$ was added in one portion at $30^{\circ} \mathrm{C}, 20 \mathrm{~min}, \mathrm{Et}_{2} \mathrm{O}$, total volume $(2.5 \mathrm{~mL})$, Ar. b) $\mathrm{GC}$ yield using $n$-hexadecane. c) [DIPrim] $\left.\mathrm{FeBr}_{3}\right] \cdot \mathrm{C}_{4} \mathrm{H}_{8} \mathrm{O}(3.0 \mathrm{~mol} \%), 4-\mathrm{MeC} \mathrm{H}_{4} \mathrm{MgBr}$ was added in one portion at $0^{\circ} \mathrm{C}$, the reaction solution was stirred for $2 \mathrm{~min}$ and then refluxed for $30 \mathrm{~min}$, ref [25]. d) [bmim] [ $\left.\mathrm{FeCl}_{4}\right](5 \mathrm{~mol} \%), 10 \mathrm{~min}, 0^{\circ} \mathrm{C}$, ref [12]. e) $\left[\mathrm{Fe}(\mathrm{IPr}) \mathrm{Br}_{3}\right](\mathrm{HIPr})_{3} \cdot \mathrm{C}_{7} \mathrm{H}(1.0 \mathrm{~mol} \%), 4-\mathrm{MeC}_{6} \mathrm{H}_{4} \mathrm{MgBr}$ was added in one portion at $0^{\circ} \mathrm{C}$, the reaction solution was stirred for 2 min and then refluxed for 30 min, ref [25]. 
employed (Table 3, entries 8 and 9). The differences in activity among $\mathbf{1}, \mathbf{3}-\mathbf{5}$ and $[\mathrm{bmim}]\left[\mathrm{FeCl}_{4}\right]$ (Table 3, entry 11) [12] suggest that a more steric bulkiness provide by the $N$-substituents should be of benefit to their higher catalytic activity, which can facilitate the reductive elimination to form the desired cross-coupling product together with impose a positive effect to suppress $\beta$-H elimination [33]. Replacement of the anion from $\left[\mathrm{FeCl}_{4}\right]^{-}$to $\left[\mathrm{FeBr}_{4}\right]^{-}$was also detrimental to performance, with $\mathbf{2}$ and $\mathbf{6}$ providing lower yields than those obtained with $\mathbf{1}$ and $\mathbf{5}$ (Table 3, entries 6 and 10), respectively. Notably, the present Fe(III)-based complex, i.e. 2, showed better performance than the Fe(II) counterpart [DIPrim] $\left[\mathrm{FeBr}_{3}\right] \cdot \mathrm{C}_{4} \mathrm{H}_{8} \mathrm{O}$ reported previously (Table 3, entries 5 and 6) [25]. This is the same pattern as that previously reported with $\mathrm{FeCl}_{3}$ /phosphine and $\mathrm{FeCl}_{2} /$ phosphine systems [33]. However, the catalytic activity of $\mathbf{2}$ is somewhat lower than the $\mathrm{Fe}(\mathrm{II})$ counterpart containing a $N$-heterocyclic carbene ligand (Table 3 , entries 5 and 12) [25].

It is worthy of note that the present cross-coupling reaction could be performed successfully at the mild temperature of $30^{\circ} \mathrm{C}$, and that the Grignard reagent could be added in a single portion at room temperature without the requirement for slow addition via a syringe pump. Furthermore, the catalytic activity of $\mathbf{1}$ or $\mathbf{3}$ was compared with other related iron(III)-based catalysts reported in the literature. Normally, $2 \mathrm{~mol} \%-5 \mathrm{~mol} \%$ or higher loadings of the iron complexes were usually required to achieve satisfactory yields for reactions similar to those shown in Equation 1 [2-12,33]. Therefore, the present results suggest that $\mathbf{1}$ and 3 might be among the most efficient precatalysts for the cross-coupling reaction of aryl Grignard reagents with alkyl halides bearing $\beta$-hydrogens.

\section{Conclusions}

A family of easily synthesized and easy-to-handle iron(III)containing imidazolium salts $[\mathrm{DRim}][\mathrm{FeX}]_{4}$ have been developed as excellent catalysts for the cross-coupling of aryl Grignard reagents with alkyl halides bearing $\beta$-hydrogens under mild conditions. Our studies demonstrate that the modification of imidazole ring with different $N$-substituents represents a promising pathway to improve the catalytic activity of iron(III)-containing imidazolium salts. The detailed structure-reactivity relationship study of iron(III)containing imidazolium salts as well as the scope of these iron(III)-based catalysts in other reactions are currently under investigation in our laboratory.

This work was supported by the National Natural Science Foundation of China (21172164), the Key Laboratory of Organic Chemistry of Jiangsu Province, and the Priority Academic Program Development of Jiangsu Higher Education Institutions.
1 Bolm C, Legros J, Paih J L, et al. Iron-catalyzed reactions in organic synthesis. Chem Rev, 2004, 104: 6217-6254

2 Martin R, Fürstner A. Cross-coupling of alkyl halides with aryl Grignard reagents catalyzed by a low-valent iron complex. Angew Chem Int Ed, 2004, 43: 3955-3957

3 Fürstner A, Martin R, Krause H, et al. Preparation, structure, and reactivity of nonstabilized organoiron compounds. Implications for iron-catalyzed cross coupling reactions. J Am Chem Soc, 2008, 130: 8773-8787

4 Bedford R B, Bruce D W, Frost R M, et al. Iron(III) salen-type catalysts for the cross-coupling of aryl Grignards with alkyl halides bearing $\beta$-hydrogens. Chem Commum, 2004, 2822-2823

5 Martin R B, Betham M, Bruce D W, et al. Iron nanoparticles in the coupling of alkyl halides with aryl Grignard reagents. Chem Commun, 2006, 1398-1400

6 Chowdhury R R, Crane A K, Fowler C, et al. Iron(III) aminebis(phenolate) complexes as catalysts for the coupling of alkyl halides with aryl Grignard reagents. Chem Commun, 2008, 94-96

7 Qian X, Dawe L N, Kozak C M. Catalytic alkylation of aryl Grignard reagents by iron(III) amine-bis(phenolated) complexes. Dalton Trans, 2011, 40: 933-943

8 Reckling A M, Martin D, Dawe L N, et al. Structure and C-C cross-coupling reactivity of iron(III) complexes of halogenated amine-bis(phenolate) ligands. J Organomet Chem, 2011, 696: 787794

9 Hasan K, Dawe L N, Kozak C M. Synthesis, structure, and C-C cross-coupling activity of (amine)bis(phenolato)iron(acac) complexes. Eur J Inorg Chem, 2011, 4610-4621

10 Nagano T, Hayashi T. Iron-catalyzed Grignard cross-coupling with alkyl halides possessing $\beta$-hydrogens. Org Lett, 2004, 6: 1297-1299

11 Cahiez G, Habiak V, Duplais C, et al. Iron-catalyzed alkylations of aromatic Grignard reagents. Angew Chem Int Ed, 2007, 46: 43644366

12 Bica K, Gaertner P. An iron-containing ionic liquid as recyclable catalyst for aryl Grignard cross-coupling of alkyl halides. Org Lett, 2006, 8: 733-735

13 Alexznder M V, Khandekar A C, Samant S D. Sulfonylation reactions of aromatics using $\mathrm{FeCl}_{3}$-based ionic liquids. J Mol Catal A, 2004, 223: 75-83

14 Chen X, Peng Y. Chloroferrate(III) ionic liquid: Efficient and recyclable catalyst for solvent-free synthesis of 3,4-dihydropyrimidin2(1H)-ones. Catal Lett, 2008, 122: 310-313

15 Nguyen M D, Nguyen L V, Jeon E H, et al. Fe-containing ionic liquids as catalysts for the dimerization of bicycle[2.2.1]hepta-2,5-diene. J Catal, 2008, 258: 5-13

16 Li H M, Zhu W S, Wang Y, et al. Deep oxidative desulfurization of fuels in redox ionic liquids based on iron chloride. Green Chem, 2009, 11: $810-815$

17 Wang H, Yan R Y, Li Z X, et al. Fe-containing magnetic ionic liquid as an effective catalyst for the glycolysis of poly(ethylene terephthalate). Catal Commun, 2010, 11: 763-767

18 Gao J, Wang J Q, Song Q W, et al. Iron(III)-based ionic liquid-catalyzed regioselective benzylation of arenas and heteroarenes. Green Chem, 2011, 13: 1182-1186

19 Olivier-Bourbigou H, Magna L, Morvan D. Ionic liquids and catalysis: Recent progress from knowledge to applications. Appl Catal A, 2010, 373: 1-56

$20 \mathrm{Hu}$ X B, Sun Y, Mao J Y, et al. Theoretical study on the structurereactivity relationships of acetylacetone-Fe catalyst modified by ionic compound in C-H activation reaction. J Catal, 2010, 272: 320-332

21 Abbott A P, Frisch G, Ryder K S. Metal complexation in ionic liquids. Annu Rep Prog Chem, Sect A, 2008, 104: 21-45

22 Bäcker T, Breunig O, Valldor M, et al. In-situ crystal growth and properties of the magnetic. Cryst Growth Des, 2011, 11: 2564-2571

23 Wang K F, Zhang L, Zhuang R R, et al. An iron(III)-containing ionic liquid: Characterization, magnetic. Transition Met Chem, 2011, 36: 785-791

24 Yan $\mathrm{C} \mathrm{H}$, Wang L L, Gao $\mathrm{H} \mathrm{H}$, et al. An efficient and recyclable iron(III)-containing imidazolium salt catalyst for cross-coupling of 
aryl Grignard reagents with alkyl halides. Chin Sci Bull, 2012, 57: 1953-1958

25 Gao H H, Yan C H, Tao X P, et al. Synthesis of anionic iron(II) complex bearing an $\mathrm{N}$-heterocyclic carbine ligand and its catalysis for aryl Grignard cross-coupling of alkyl halides. Organometallics, 2010, 29: 4189-4192

26 Jafarpour L, Stevens E D, Nolan S P. A sterically demanding nucleophilic carbene: 1,3-bis(2,6-diisopropylphenyl)imidazol-2ylidene). Thermochemistry and catalytic application in olefin metathesis. J Organomet Chem, 2000, 606: 49-54

27 Herrmann W A, Böhm V P W, Gstöttmayr C W K, et al. Synthesis, structure and catalytic application of palladium(II) complexes bearing $\mathrm{N}$-heterocyclic carbenes and phosphines. J Organomet Chem, 2001, 617-618: 616-628

28 Arduengo III A J. Preparation of 1,3-disubstituted imidazolium salts. US Pat, 5077 414, 1991-12-31
29 Sitze M S, Schreiter E R, Patterson E V, et al. Ionic liquids based on $\mathrm{FeCl}_{3}$ and $\mathrm{FeCl}_{2}$. Raman scattering and ab initio calculations. Inorg Chem, 2001, 40: 2298-2304

30 Avery J S, Burbride C D, Goodume D M L. Raman spectra of tetrahalo-anions of $\mathrm{Fe}^{\mathrm{III}}, \mathrm{Mn}^{\mathrm{II}}, \mathrm{Fe}^{\mathrm{II}}, \mathrm{Cu}^{\mathrm{II}}$ and $\mathrm{Zn}^{\mathrm{II}}$. Spectrochimica Acta, 1968, 24A: 1721-1726

31 Lowe C B, Schultz A J, Shaviv R, et al. Magnetochemistry of the tetrahaloferrate(III) ions. 7. Crystal structure and magnetic ordering in (pyridinium) ${ }_{3} \mathrm{Fe}_{2} \mathrm{Br}_{9}$. Inorg Chem, 1994, 33: 3051-3054

32 Steiner T. Hydrogen-bond distances to halide ions in organic and organometallic crystal structures: Up-to-date database study. Acta Cryst, 1998, B54: 456-463

33 Beford R B, Betham M, Bruce D W, et al. Iron-phosphine, -phosphite, -arsine, and -carbene catalysts for the coupling of primary and secondary alkyl halides with aryl Grignard reagents. J Org Chem, 2006, 71: 1104-1110

Open Access This article is distributed under the terms of the Creative Commons Attribution License which permits any use, distribution, and reproduction in any medium, provided the original author(s) and source are credited. 